The Journal of Bone E Joint Surgery


This is an enhanced PDF from The Journal of Bone and Joint Surgery

The PDF of the article you requested follows this cover page.

\title{
Treatment of congenital dislocation of the hip by the Pavlik harness. Mechanism of reduction and usage
}

K Iwasaki

J Bone Joint Surg Am. 1983;65:760-767.

This information is current as of November 5, 2009

Reprints and Permissions

Click here to order reprints or request permission to use material from this article, or locate the article citation on jbjs.org and click on the [Reprints and Permissions] link.

Publisher Information

The Journal of Bone and Joint Surgery

20 Pickering Street, Needham, MA 02492-3157

www.jbjs.org 


\title{
Treatment of Congenital Dislocation of the Hip by the Pavlik Harness
}

\author{
Mechanism of Reduction and USAGE \\ BY KATSURO IWASAKI, M.D.*, NAGASAKI CITY, JAPAN \\ From the Department of Orthopaedic Surgery, Nagasaki University School of Medicine, Nagasaki City
}

\begin{abstract}
The Pavlik harness was used in the treatment of complete congenital dislocation of one or both hips in a series of infants, on either an outpatient or an inpatient basis. The results in the two groups were compared. For the children treated as outpatients the incidence of avascular necrosis of the femoral head was 7.2 per cent and for the group treated as inpatients the rate was 28 per cent. Application of the Pavlik harness allowed reduction of the hip by shifting the femoral head first to the posterior part of the acetabulum through flexion of the hip, followed by movement of the femoral head anteriorly into the acetabulum through abduction of the hip, which is possible because of stretching of the adductor muscles by the weight of the lower extremity. When the reduction is obtained by forced abduction there is a greater danger of avascular necrosis of the femoral head.
\end{abstract}

Treatment of congenital dislocation of the hip with the Pavlik harness is generally done on an outpatient basis, and this is considered to be an advantage of this method. Since the adjustment of the harness after its application is mostly carried out at home by the child's mother, the question always arises as to how well the harness is being used. Since the report by Pavlik, many studies of this method of treatment have been done. Reduction has been reported to be unsuccessful in 10 to 20 per cent of the patients ${ }^{6,7,10-12}$, allegedly because the harness was not used properly ${ }^{2.4 .12}$. Since 1976, therefore, the patients seen at my clinic have been hospitalized and the staff has controlled adjustment of the Pavlik harness. The therapeutic results thus obtained were considerably different from those in patients treated on an outpatient basis at the clinic.

In this report I compare two groups of patients, one treated on an outpatient basis and the other, as inpatients. The mechanism of reduction of the dislocation using a Pavlik harness was also studied.

\section{Materials and Methods}

A dislocation was diagnosed by these clinical signs:

* Department of Orthopaedic Surgery, Nagasaki University School of Medicine, 7-1, Sakamoto-Machi, Nagasaki City, Japan. limited abduction, shortening of the affected extremity, or a positive click sign. It was confirmed by roentgenograms showing lateral displacement of the proximal end of the femur, interruption of the Shenton line, or the presence of a false acetabulum.

Between 1966 and the first half of 1976, 240 completely dislocated hips of 204 patients were treated on an outpatient basis at the Department of Orthopaedic Surgery, Nagasaki University School of Medicine. Patients with subluxation, acetabular dysplasia, teratological dislocation, myelodysplasia, or arthrogryposis were excluded from this study.

The ages of the patients at the beginning of treatment ranged between one and seven months and averaged four months (Table I). For the outpatients, as soon as the diagnosis was made the Pavlik harness was applied and the patient was checked at intervals of three to seven days. Reduction and stability were evaluated by clinical signs such as the absence of limited abduction and of the click sign, as well as by roentgenograms that were made once a week until reduction was achieved. After the dislocation was reduced, roentgenographic and clinical examinations were carried out once a month. When a neutral anteroposterior roentgenogram, made with the hip in extension, showed a concentric position of the femoral head the hip was considered stable. After four to eight months, when the shallow acetabulum was seen to have improved roentgenographically, the harness was removed.

I tried to determine the rate of reduction after initial treatment with the Pavlik harness in all of these patients, the incidence of avascular necrosis of the femoral head in 193 hips of 164 patients who were followed for more than one year, and the incidence of anatomical healing in 153 hips of 131 patients who were followed for more than five years.

Forty patients were lost to follow-up after one year and seventy-three, after five years. Most of them had moved to other cities without leaving a new address.

The criteria that were used in establishing the diagnosis of avascular necrosis were those of Salter et al.: (1) failure of appearance of the ossific nucleus of the femoral head for one year or longer after reduction, (2) failure of growth of an existing ossific nucleus for one year or longer 
TABLE I

Results of Treatment with the Pavlik Harness in the Outpatient Group

\begin{tabular}{|c|c|c|c|c|c|c|c|c|c|}
\hline \multirow{2}{*}{$\begin{array}{c}\text { Age of the Patients } \\
\text { at the Start } \\
\text { of Treatment } \\
\text { (Days) }\end{array}$} & \multirow{2}{*}{$\begin{array}{c}\text { No. of } \\
\text { Hips Treated }\end{array}$} & \multicolumn{2}{|c|}{ Reduction } & \multicolumn{3}{|c|}{$\frac{\text { Hips Followed for One Year }}{\begin{array}{c}\text { Avascular } \\
\text { Necrosis }\end{array}}$} & \multicolumn{3}{|c|}{$\begin{array}{c}\text { Hips Followed for Five Years } \\
\begin{array}{c}\text { Anatomical } \\
\text { Healing }\end{array}\end{array}$} \\
\hline & & $\overline{\text { No. }}$ & Per Cent & Total No. & No. & Per Cent & Total No. & No. & Per Cent \\
\hline $31-60$ & 29 & 24 & 82.7 & 22 & 3 & 13.6 & 20 & 18 & 90.0 \\
\hline $61-90$ & 53 & 43 & 81.1 & 43 & 4 & 9.3 & 38 & 32 & 84.3 \\
\hline $91-120$ & 73 & 67 & 91.1 & 63 & 4 & 6.3 & 46 & 40 & 87.0 \\
\hline $121-150$ & 43 & 37 & 86.0 & 37 & 2 & 5.4 & 27 & 22 & 81.5 \\
\hline $151-180$ & 30 & 23 & 76.6 & 21 & 0 & 0 & 15 & 11 & 73.4 \\
\hline $181-210$ & 12 & 7 & 58.3 & 7 & 1 & 14.2 & 7 & 4 & 57.2 \\
\hline \multicolumn{10}{|l|}{ Total } \\
\hline Hips & 240 & 201 & 83.7 & 193 & 14 & 7.2 & 153 & 127 & 83.0 \\
\hline Patients & 204 & 179 & & 164 & & & 131 & & \\
\hline
\end{tabular}

after reduction, (3) broadening of the femoral neck during the year after reduction, (4) increased roentgenographic density of the femoral head followed by the roentgenographic appearance of fragmentation, and (5) residual deformity of the femoral head and neck (coxa magna, coxa plana, coxa vara, or a short broad femoral neck) when reossification was complete.

From the latter half of 1976 to 1979 , forty-four patients (fifty dislocated hips) were treated with the Pavlik harness as inpatients. In the latter half of 1976 and during 1979 patients who had severe adductor contracture clinically or severe displacement of the femoral head roentgenographically, or both, were hospitalized. Thus, of the twenty-nine infants (thirty-one dislocated hips) who were seen at our hospital during that period, only eleven (thirteen hips) were treated as inpatients. In contrast, during the period between 1977 and 1978 I tried to hospitalize as many patients as possible, independent of the severity of the clinical or roentgenographic signs. Thus, during this latter time-period of 1977 and 1978 thirty-three of forty infants (thirty-seven of forty-five dislocated hips) were treated as inpatients.

After application of the harness the hospitalized patients were made to lie supine, and they were not allowed to change this position even for nursing or bathing. Care was taken to prevent the diaper, diaper-cover, and clothing from restricting spontaneous movements of either lower extremity.

These inpatients were divided into three subgroups. Subgroup 1 consisted of fourteen hips (eleven patients) in which the attempt at reduction in the outpatient clinic had been unsuccessful. The requirement for hospitalization was met when reduction was not achieved within three to four weeks after the application of the harness. At the time of admission to the hospital the ages of the eleven patients ranged from two to six months and averaged 4.1 months (Table II). Subgroup 2 consisted of twenty-five hips in twenty-three patients for whom no ambulatory treatment was carried out and who were hospitalized for treatment. The age range at the beginning of treatment was from two to six months and averaged 4.4 months (Table II). Sub- group 3 consisted of eleven hips (ten patients) that were treated similarly to those in subgroup 2 , with the only difference being that at the beginning of treatment the patients were between six and twelve months old (average, eight months) (Table II).

In order to clarify the process of reduction after application of the harness, attention was paid to signs of malaise and poor appetite in the infants as well as to the position and spontaneous movements of the lower extremities. The babies were observed clinically and, when indicated, records (photographs or eight-millimeter movies) were obtained.

TABLE II

Ages of Hospitalized Patients at Start of Treatment

\begin{tabular}{|c|c|c|c|c|}
\hline \multirow[b]{2}{*}{$\begin{array}{l}\text { Age } \\
\text { (Days) }\end{array}$} & \multicolumn{2}{|c|}{ No. of Subgroup-1 Patients } & \multirow{2}{*}{$\begin{array}{c}\text { No. of } \\
\text { Subgroup- } \\
2 \text { Patients }\end{array}$} & \multirow{2}{*}{$\begin{array}{l}\text { No. of } \\
\text { Subgroup- } \\
3 \text { Patients }\end{array}$} \\
\hline & $\begin{array}{l}\text { At Application } \\
\text { of Pavlik Harness }\end{array}$ & $\begin{array}{l}\text { At Admission } \\
\text { to the Hospital }\end{array}$ & & \\
\hline $31-60$ & 1 & & & \\
\hline 61.90 & 3 & 1 & 4 & \\
\hline $91-120$ & 5 & 2 & 10 & \\
\hline $121-150$ & 4 & 6 & 7 & \\
\hline $151-180$ & 1 & 4 & 4 & \\
\hline 181.210 & & 1 & & 8 \\
\hline $211-240$ & & & & 1 \\
\hline 241.270 & & & & \\
\hline $271-300$ & & & & 1 \\
\hline $301-330$ & & & & \\
\hline $331-360$ & & & & 1 \\
\hline
\end{tabular}

In each of the three subgroups, additional studies were conducted to determine the necessity of applying traction before using the Pavlik harness, the presence of complications such as avascular necrosis and the acetabular dysplasia at one year after reduction, and the incidence of anatomical healing at three years after reduction.

\section{Results}

\section{Outpatients}

Table I summarizes the rates of success with the Pavlik harness according to the ages of these patients at the beginning of treatment. Reduction was achieved in about 85 per cent of the children who were less than six months 


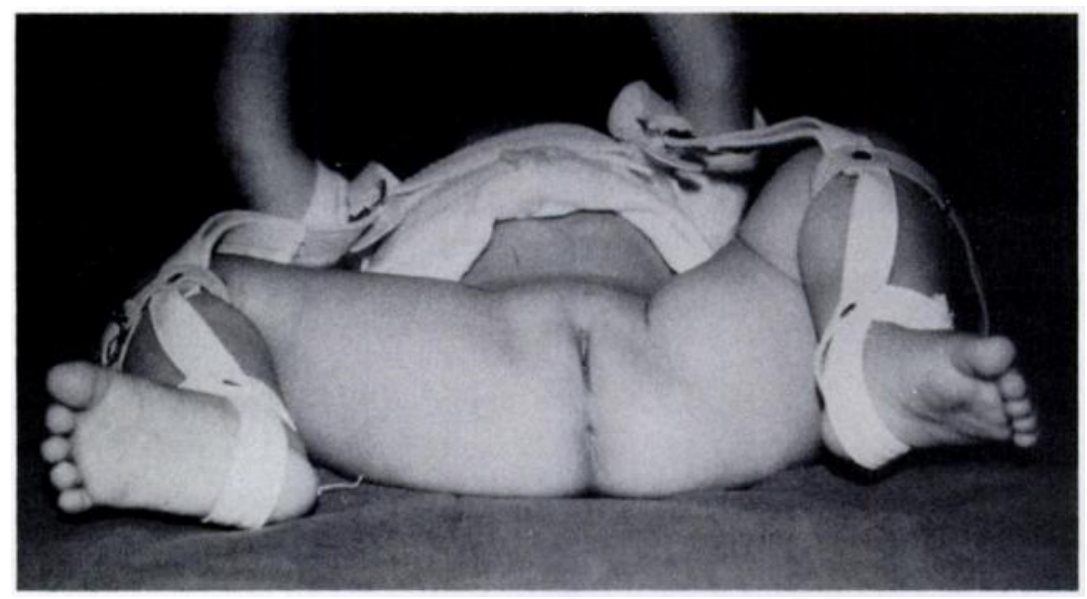

FiG. 1

In the left hip of this patient treated with the Pavlik harness, abduction is not full and the dislocation remains unreduced.

old, but the rate decreased to 58 per cent in those older than six months. The over-all rate of reduction was 83.7 per cent.

Avascular necrosis of the femoral head was seen in fourteen ( 7.2 per cent) of the 193 hips ( 164 patients) that were followed for more than one year (Table I). Roentgenographic evidence of the necrosis appeared within the first year after reduction in all fourteen hips. Roentgenographic changes of avascular necrosis also occurred in two normal contralateral hips during treatment of the dislocated hip, but these changes improved within the next four years. The incidence of avascular necrosis was higher in the younger patients (Table I).

Roentgenograms of 153 hips ( 131 patients) that were followed for more than five years revealed anatomical healing in 127 hips in 109 patients, an incidence of 83 per cent (Table I). Deformity of the femoral head or acetabular dysplasia, or both, persisted in twenty-six hips (twentytwo patients), an incidence of 17 per cent. Of the fourteen hips that showed avascular necrosis, eight had coxa plana with acetabular dysplasia, four had slight deformity of the femoral head, and two showed no abnormality. In the fourteen hips that did not have avascular necrosis, the degree of acetabular dysplasia was slight.

\section{Hospitalized Patients}

After application of the harness, these patients had limitation of movement of both hips, including incomplete abduction. On the uninvolved side, however, activity and range of abduction were restored to normal in one or two days, whereas on the affected side the range of abduction was incomplete and scarcely any spontaneous movement of the abnormal lower extremity occurred as long as the dislocation remained unreduced (Fig. 1). Such restriction of abduction, which gradually disappears in subsequent weeks, is most obvious when the infant is asleep. As sleep deepens and muscle tone decreases, the angle of abduction gradually increases until the baby awakens and cries, at which time the angle returns to what it was before the baby went to sleep. Stretching of the adductor muscle probably wakens the baby because of pain. When the baby again falls asleep, the angle of abduction increases and the baby wakes again. This might be repeated several times during the night for several nights. When treatment is successful the restriction of abduction gradually disappears, at which time the dislocation is reduced. In the present series, reduction was accomplished in 75 per cent of the patients within seven days after application of the harness.

As a rule, after the harness was applied no active movement of the lower extremities was observed, except for flexion and extension of the ankle joint, until reduction was accomplished or even until a few weeks later. Meanwhile the child frequently cried and had a poor appetite.

TABLE III

Results of Treatment with the Pavlik Harness for the Hospitalized Patients

\begin{tabular}{|c|c|c|c|c|c|c|}
\hline & \multicolumn{2}{|c|}{$\begin{array}{l}\text { Avascular } \\
\text { Necrosis*† }\end{array}$} & \multicolumn{2}{|c|}{$\begin{array}{l}\text { Acetabular } \\
\text { Dysplasia* }\end{array}$} & \multicolumn{2}{|c|}{$\begin{array}{c}\text { Anatomical } \\
\text { Healing } \ddagger\end{array}$} \\
\hline & No. & Per Cent & No. & Per Cent & No. & Per Cent \\
\hline $\begin{array}{r}\text { Subgroup } 1 \\
\text { (14 hips) }\end{array}$ & 3 & 21 & 5 & 36 & 8 & 57 \\
\hline $\begin{array}{r}\text { Subgroup } 2 \\
\text { (25 hips) }\end{array}$ & 10 & 40 & 3 & 12 & 15 & 60 \\
\hline $\begin{array}{r}\text { Subgroup } 3 \\
\text { (11 hips) }\end{array}$ & 1 & 9 & 5 & 45 & 5 & 55 \\
\hline Total & 14 & 28 & 13 & 26 & 28 & 56 \\
\hline
\end{tabular}

* At one year after reduction.

+ Includes patients with both acetabular dysplasia and avascular necrosis.

$\ddagger$ At three years after reduction.

Coincident with the reduction, swelling occasionally appeared in the area of the hip joint and persisted for at least one week (Fig. 2), so that passive movement of the hip joint caused the baby to cry.

Spontaneous movement of the lower extremity on the affected side usually appeared about one week after reduction, but this interval ranged from five to twenty days. Flexion and extension of the knee appeared first, with the hip joint in the abducted position, and was followed by ac- 


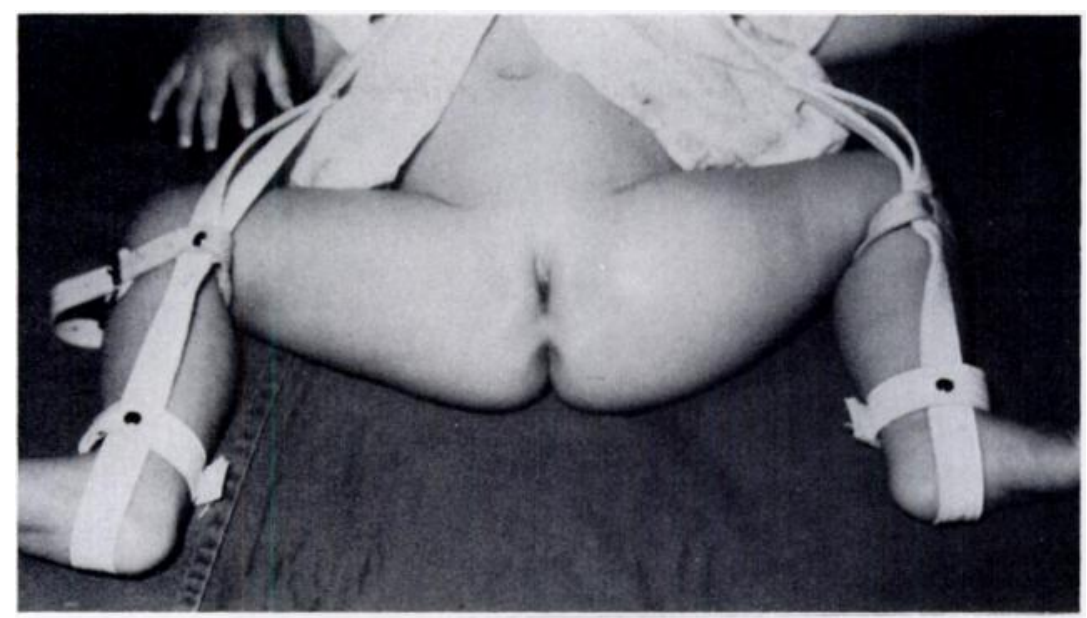

FIG. 2

Swelling appeared in the area of the left hip joint after reduction with the Pavlik harness.

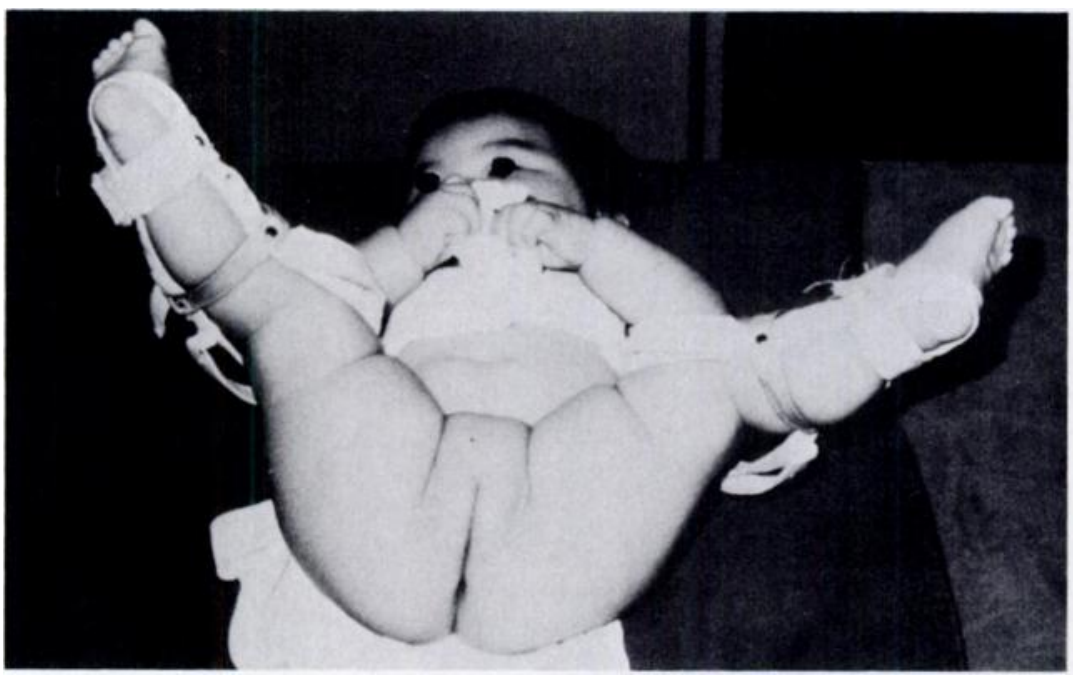

FIG. 3

Active spontaneous movement of the hip indicates stabilization of the joint.

tive flexion and extension of the hip. Then spontaneous active rotation and adduction of the hip was observed, indicating stabilization of the joint. It usually took about one month for these motions to become normal (Fig. 3).

All of the children who were hospitalized had a successful reduction with the use of the Pavlik harness but ten of them had required traction in addition (Table III). Five of these ten patients had had unsuccessful treatment with the harness as outpatients. In twenty-four of twenty-five hips in twenty-three patients who were less than six months old and who were hospitalized at random for treatment (subgroup 2), reduction was uneventfully accomplished with the Pavlik harness alone. However, five of fourteen hips in subgroup 1, four of eleven hips in subgroup 3 , and one hip in subgroup 2 required traction of the lower extremities before definitive application of the Pavlik harness. The five hips in subgroups 2 and 3 had severe displacement or contractures.

Patients in whom reduction was not possible within a few days after application of the Pavlik harness showed the following characteristics. First, the child assumed an oblique posture with the affected hip joint adducted (Fig. 4-A). In order to correct this obliquity, a pillow was used to abduct the hip and achieve reduction (Fig. 4-B). Second, the knee joint in these patients assumed an angle of flexion of more than 90 degrees (Fig. 5-A), and this was reduced by the application of a splint at the popliteal fossa (Fig. 5-B). Babies older than the age of six months can sit or stand while wearing the harness (Fig. 6-A), but a supine position is forced by the use of a restraining belt and reduction is thus facilitated (Fig. 6-B).

Traction was employed in the following situations: (1) when reduction was not achieved by the Pavlik harness within seven to ten days even after the described procedures were tried, (2) when the medial corner of the metaphysis was superior to the Hilgenreiner line ${ }^{1}$, and (3) when there was a severe flexion and adduction contracture of the hip with pronounced dislocation. These factors were present mainly in the outpatients who had had inadequate application of the harness. 


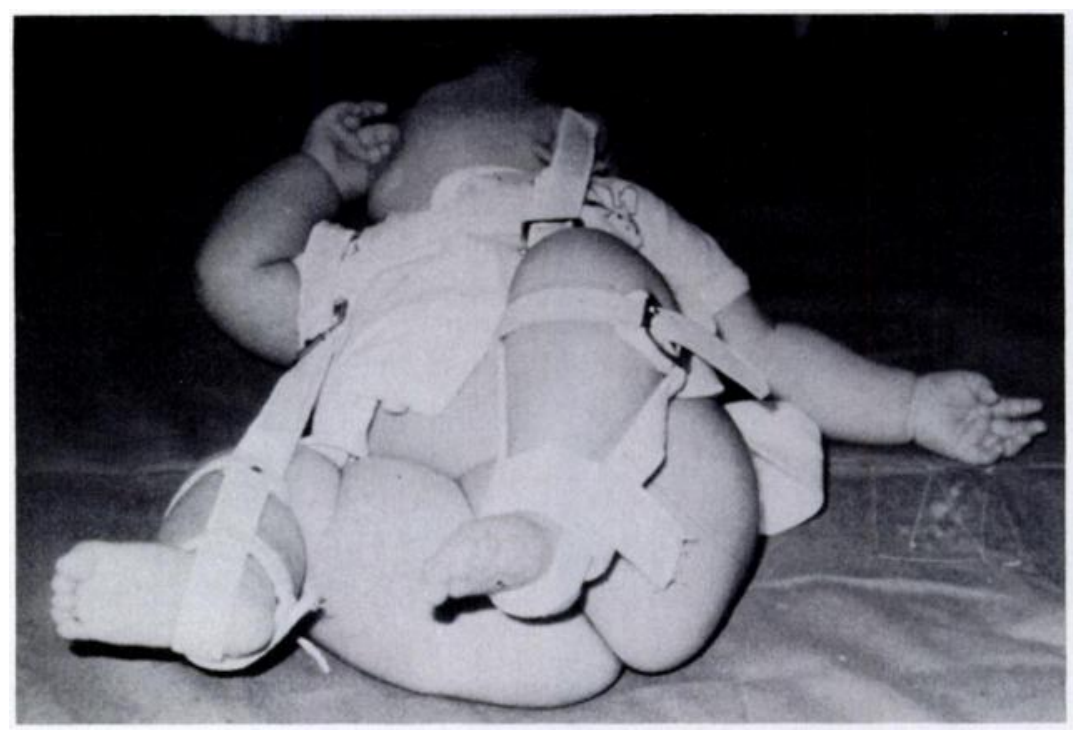

FIG. 4-A

This child with a dislocation of the left hip assumes an oblique posture after application of the Pavlik harness.



FIG. 4-B

The oblique posture is corrected by a pillow placed behind the back.

The customary regimen of traction used at our institution consisted of skin traction with the hip extended and abducted to not more than 45 degrees. The force of traction was between one and two kilograms. When the medial corner of the metaphysis descended to the level of the Hilgenreiner line, traction was discontinued and the Pavlik harness was applied.

The roentgenographic examination that was carried out one year after reduction revealed avascular necrosis of the femoral capital epiphysis in fourteen of the patients who had been hospitalized (Table III). This complication was seen in ten of twenty-five hips of patients who were less than six months old (subgroup 2), and the over-all incidence in the hospitalized patients was 28 per cent. Avascular necrosis was especially frequent in patients in whom there was no spontaneous movement of the lower extremities for more than one month after reduction and in those with marked swelling.
Acetabular dysplasia, on the other hand, was mainly seen in the hips of patients who were more than six months old at the start of treatment and in patients who had required traction.

The incidence of anatomical healing after three years of follow-up was 56 per cent for the hospitalized patients (Table III). Deformity of the femoral head persisted in twelve of fourteen hips in which avascular necrosis had occurred one year after reduction, and acetabular dysplasia continued in ten of thirteen hips.

\section{Discussion}

Compared with several other devices in use, the Pavlik harness is simple and allows movements of the lower extremity other than extension, so that it is comfortable for the child. In order to achieve successful healing without complications, however, control during application is quite important. To understand how the harness works, 


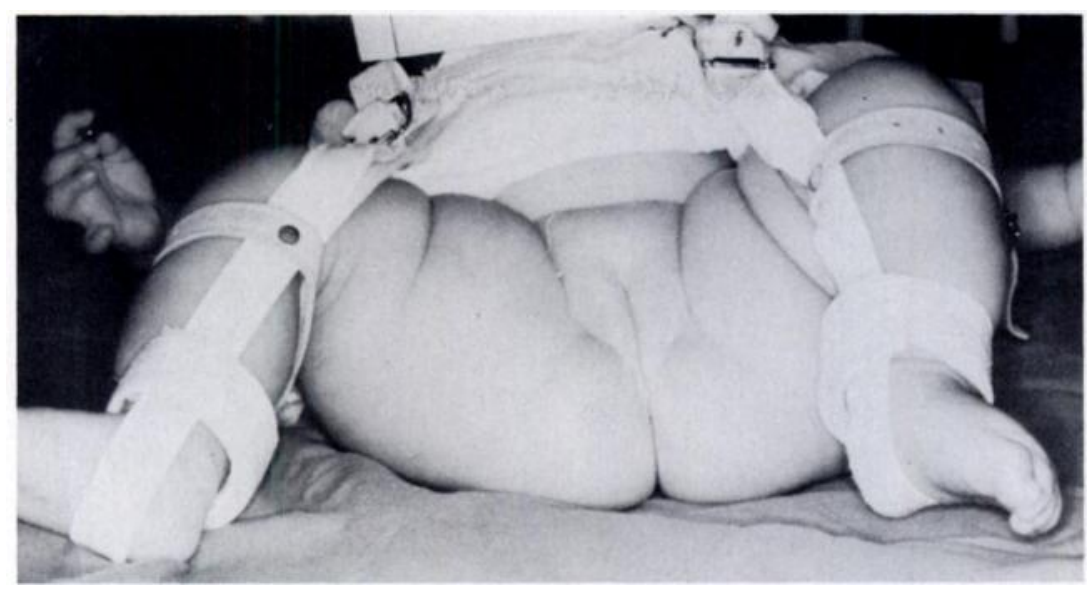

Fig. 5-A

The left knee joint on the affected side assumes a position of flexion of more than 90 degrees.



FiG. 5-B

The position of flexion is corrected by applying a splint at the popliteal fossa.

more information on the mechanism of reduction must be obtained. With reference to this, Mittelmeier pointed out the important role of activity of the quadriceps muscle and contraction of the gluteal muscles as affected by the harness. Sakaguchi and later Ramsey et al. described the activity of the hamstrings during spontaneous flexion and extension of the knee acting to reduce the dislocation. All of these reports suggested the need for spontaneous movements of the lower extremity to help to reduce the dislocation. In my observations of children after application of the harness, however, I noted scarcely any movement of the extremities before and immediately after reduction, contrary to the theory of reduction just described. Relief of the adductor contracture, which Pavlík regarded as indispensable for reduction, is probably accomplished not by spontaneous movement of the lower extremity, but by stretching of the adductor muscles by the weight of the lower extremity, as mentioned by Suzuki. This phenomenon is especially pronounced in a state of decreased muscle tone, as during deep sleep when the patient is supine with the hip flexed and abducted. The method of application of the harness should be one that achieves the most efficient relief of the contracture of the adductor muscles and the most abduction of the hip joint by the weight of the lower extremity. This should then ensure prompt and easy reduction.

The mechanism of reduction by means of the Pavlik harness most probably consists of a shift of the femoral head from a superior position to the posterior aspect of the acetabulum, which is promoted by flexion of the hip joint. Furthermore, when the abducted position is assumed, the weight of the lower extremity plays the important role of stretching the adductor muscles and consequently allowing the dislocated femoral head to slide anteriorly over the acetabular rim and into the acetabulum. Thus, the direction of the power acting at the time of reduction is the same as that acting during manual reduction, the only difference being the source of the power. Either the weight of the lower extremity itself or the manual power of an operator can lever the femoral head into the reduced position.

Reduction was successfully accomplished by application of the Pavlik harness in all of the hospitalized children in this series. However, comparison of these results with those in the children treated on an outpatient basis revealed two problems with the Pavlik method. First, avascular necrosis of the femoral head was found in 7.2 per cent of the outpatients, but the incidence was as high as 28 per cent in the children who were hospitalized. This higher 


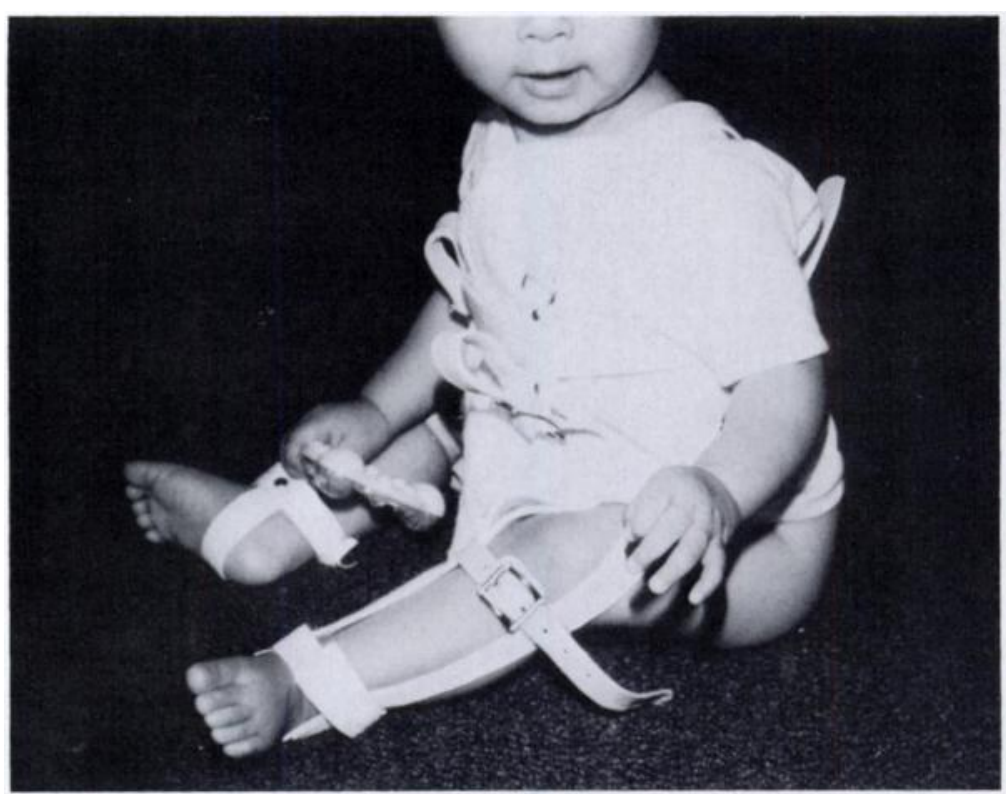

Fig. 6-A

This baby, more than six months old, is able to sit after the harness is applied.

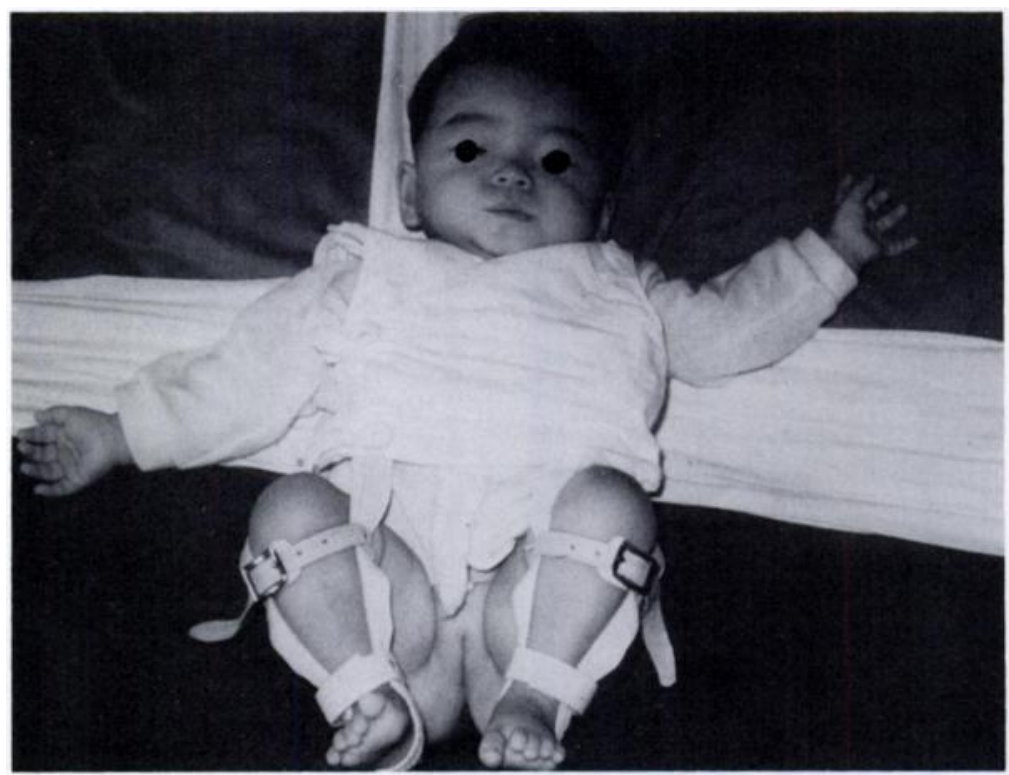

Fig. 6-B

In order to force the child into a supine position, a restraining belt is used.

rate was similar to the incidence of avascular necrosis in a series of patients treated at the Nagasaki University by the Lorenze method. The second problem was that anatomical healing was difficult to achieve in older children and in children with severe displacement. Attempts at reduction in these patients were often unsuccessful in the outpatient group, although when that became evident the children were hospitalized and reduction was achieved through the use of a restraining band as well as traction prior to application of the Pavlik harness.

These observations suggest two important points to bear in mind in the treatment of congenital dislocation of the hip with the Pavlik harness: (1) in patients with con- genital dislocation of the hip that cannot be reduced easily organic and irreversible changes have already occurred in the hip joint so that complete recovery is not always possible even after reduction, and (2) in patients in whom attempts at reduction are too strenuous - that is, when the limb is forced into abduction in order to apply the whole weight of the lower extremity on the hip joint - even the Pavlik harness is not always a safe and gentle method; malaise on the part of the child and swelling of the hip joint may become evident if the hip is in a forced position. In children with severe symptoms of malaise and pain on motion of the hip, avascular necrosis of the femoral head is apt to occur. This is probably due to the excessive abduc- 




FIG. 7

Pillows are applied under the knees to reduce the angle of abduction.

tion of the hip joint beyond the safe zone described by Ramsey et al., so that excessive compression is applied to the femoral head, causing avascular necrosis. Such phenomena can easily occur when application of the harness is improper.

What is the proper method of application of the harness? After application, the position of the lower extremities should be adjusted to ensure that there is 90 to 100 degrees of flexion of the hip joint as the fundamental position. Subsequent adjustments should be based on careful observation of the position of the extremities and of the systemic reaction of the child. A constant oblique posture and excessive flexion of the knee are unacceptable. If the child is able to sit and stand, reduction by means of the harness alone is impossible; such children must be kept recumbent and the weight of the lower extremity must be directed toward abduction (Figs. 4-A through 6-B), with the degree and duration of such weight being most important. The child will respond to an application of unnatural force in his or her own way, as has already been described, but, as shown in Figure 7, pillows may be applied to reduce the angle of abduction or traction may be required.

In the children who were treated as outpatients, the incidence of avascular necrosis of the femoral head was low, probably because the external power acting on the femoral head was decreased when the mother held the baby or carried him or her on her back in response to the crying. Regulation of the abduction force might be exerted in this way in outpatient treatment.

In the treatment of congenital dislocation of the hip in infancy, the Pavlik harness should be employed in the outpatient clinic first. If successful reduction is not obtained, the next step should be traction and then application of the Pavlik harness during hospitalization.

\section{References}

1. Gage, J. R., and Winter, R. B.: Avascular Necrosis of the Capital Femoral Epiphysis as a Complication of Closed Reduction of Congenital Dislocation of the Hip. A Critical Review of Twenty Years' Experience at Gillette Children's Hospital. J. Bone and Joint Surg., 54-A: 373-388, March 1972

2. IsHiDA, K.: [Investigation on the Unreduced Cases by Pavlik Harness in Congenital Dislocation of the Hip.] Rinsho Seikei Geka [Clin. Orthop. Surg. I, 13: 204-211, 1978 .

3. Mittelmeier, Heinz: Beitrag zur funktionellen Therapie und Spontanreposition der angeborenen Luxationshüfte mit Spreizhöschen und Pavlikbandage. Zugleich eine Kritik der klassischen Behandlungstechnik mit manueller Reposition in Narkose und Gipsretention. Arch. orthop. Unfall-Chir., 52: 465-522, 1961.

4. Mubarak, Scott; Garfin, Steven; Vance, Raymond; McKinnon, Bert; and Sutherland, David: Pitfalls in the Use of the Pavlik Harness for Treatment of Congenital Dysplasia, Subluxation, and Dislocation of the Hip. J. Bone and Joint Surg., 63-A: 1239-1248, Oct. 1981.

5. PAvlík, ARnold: Die funktionelle Behandlungsmethode mittels Riemenbügel als Prinzip der konservativen Therapie bei angeborenen Hüftgelenksverrenkungen der Säuglinge. Zeitschr. Orthop., 89: 341-352, 1957.

6. Ramsey, P. L.; Lasser, Stephen; and MacEwen, G. D.: Congenital Dislocation of the Hip. Use of the Pavlik Harness in the Child during the First Six Months of Life. J. Bone and Joint Surg., 58-A: 1000-1004, Oct. 1976.

7. Sakaguchi, R.: [Treatment of Congenital Dislocation of the Hip in Infants.] Rinsho Seikei Geka [Clin. Orthop. Surg.], 2: 679-707, 1967.

8. Salter, R. B.; Kostuik, J.; and Dallas, S.: Avascular Necrosis of the Femoral Head as a Complication of Treatment for Congenital Dislocation of the Hip in Young Children: A Clinical and Experimental Investigation. Canadian J. Surg., 12: 44-61, 1969.

9. SuzuKI, R.: Complications of the Treatment of Congenital Dislocation of the Hip by the Pavlik Harness. Internat. Orthop., 3: 77-79, 1979.

10. Yamada, K.; Hachiya, M.; Sugimoto, K.; Hirai, M.; TuchiYa, K.; Furuhashi, K.; Yamamoto, M.; and Yamashita, Y.: [The Causes and Treatment of Unsuccessful CDH Cases Treated by Pavlik Bandage.] Rinsho Seikei Geka [Clin. Orthop. Surg.], 16: 278-284, 1981.

11. Yamamuro, T.; OKa, M.; and Ishida, K.: [Long Term Results of Treatment of Congenital Dislocation of the Hip with Pavlik's Harness and Its Controversial Points.] J. Japanese Orthop. Assn., 48: 796, 1974.

12. Yano, T.: [Causes of Unreduced CDH with Pavlik’s Bandage and Its Treatment.] Rinsho Seikei Geka [Clin. Orthop. Surg.], 16: 275-277, 1981 